\title{
Ph and NPK Sensor Based Soil Testing System
}

\author{
Dinesh B. Bhoyar', Amey Naik², Swati K. Mohod ${ }^{3}$ and K. D. Kulat ${ }^{4}$ \\ ${ }^{1}$ Assistant Professor, Department of ETC, Yeshwantrao Chavan College of Engineering, Nagpur, Maharashtra, \\ India, \\ ${ }^{2}$ PG Scholar, Department of ETC, Yeshwantrao Chavan College of Engineering, Nagpur, Maharashtra, India, \\ ${ }^{3}$ Assistant Professor, Department of EL, Yeshwantrao Chavan College of Engineering, Nagpur, Maharashtra, \\ India, \\ ${ }^{4}$ Professor, Department of ECE, Visvesvaraya National Institute of Technology, Nagpur, Maharashtra, India,
}

\section{ABSTRACT}

Soil is the most important part of agriculture goods production. Therefore, it is important to know its quality and health. To know about the soil's health, we need to study various nutrients of soil. The nutrients not only help us to know the health of the soil but also helps us to know which crop to be planted in the soil. In this review, we will deal with developing a system that collects data from the soil. We will be using a sensor-based system that effectively suggest crops based on the data collected and analyzed. This system provide a cost-effective alternative for current chemicalbased soil testing that is carried out in a laboratory and which may be out of reach of farmers that live in a remote area. This whole process may consume lot of time and may be sometime costlier.

KEY WORDS: SOIL HEALTH, SUGGEST BEST CROP, COST EFFECTIVE SYSTEM.

\section{INTRODUCTION}

The lack of information about the soil content affects the production of crop. This actually affects the returns of the farmer who has invested their time and money. Therefore, a system is required that can effectively tell about the crop to be planted and what care to be taken to make a good profit from production. Traditionally, the process of soil testing is done in a laboratory [D. B. Bhoyar, 2016] where it is tested chemically and results are then obtained which decides the crop that is suitable for the soil. The chemical testing method obtains mainly NPK and Ph from the soil [Nita Kamble, 2016]. NPK

\section{ARTICLE INFORMATION}

*Corresponding Author: dinesh.bhoyar23@gmail.com Received 16th Oct 2020 Accepted after revision 29th Dec 2020 Print ISSN: 0974-6455 Online ISSN: 2321-4007 CODEN: BBRCBA

Thomson Reuters ISI Web of Science Clarivate Analytics USA and Crossref Indexed Journal

\section{Clarivate
Analytics}

NAAS Journal Score 2020 (4.31)

A Society of Science and Nature Publication,

Bhopal India 2020. All rights reserved.

Online Contents Available at: http//www.bbrc.in/

Doi: $h$ ttp://dx.doi.org/10.21786/bbrc/13.14/89 means Nitrogen, phosphor, and potassium. This a very important parameter. Therefore, it is important know the $\mathrm{Ph}$ content of the soil.

The farmers take the soil sample to laboratory then laboratory officials test the sample and obtain the abovementioned parameters. This process is time consuming and also takes lots of efforts to obtain the values. Farmer may have to wait for weeks for the information about the soil. This may delay their agriculture process. Sometimes these laboratories are situated in remote areas where it becomes difficult for farmers to reach it. If they still want to access the laboratory, they need to courier it to laboratory. This very much time-consuming process. This also involves lot of money. For farmers money becomes the issue thus they have to settle with their previously planted crops. In this review we will study various parameters such as NKP, Phosphor, Zinc, and Sculpture ETC. We will purpose a system that is not only cost-effective alternative for obtaining values for above mention parameters but also will provide an effortless and less time-consuming alternative. 


\section{Related studies}

a. Measurement of soil content using a PC (PERSONAL COMPUTER) and transducer-based system: This system is built using a bunch of transducers, multiplexers and a host personal computer. The transducers collect data and send it to computer via a line in multiplexers then processes it and produces a desired output. The main disadvantage of this type of system is its bulky nature and its portability. Such systems are immobile and cannot be taken out for soil testing. It also has complex nature because use of various transducer and multiplexers and its connection with the host system. These systems also require high level of calibration before actual process begins. This system is also a much costlier system and it up gradation even costlier. It also requires a costly software for effective data collection. The development of this type of system takes lot of efforts and time. This system may not be readily available in market. It also requires market analysis before being sold in the actual market. The transducer used in the system may not be available market as bulk production option. A high maintenance cost may be required to pay as well. The software requires a trained operator to operate it. Fault detection may sometime become a headache.

b. Trans receiver-based soil nutrients detection system: This system is based on the principle of detection of nutrients in soil with the help of Tran receiver chip that detects change in resistance affected by turbidity. Transmitting chip radiates certain radiation into the soil and receiver chip receives the radiation. Based on the radiation collected by the receiving chip the amount of nutrients is detected. Unfortunately, this system also suffers from certain drawbacks. They are, actual turbidity may affect the radiation reception and false values may be obtained. While diluting the soil sample with water resistance between soil contents may increase or decrease which give false value. The trans receiver chip are costlier hence cost of system in increased as they are manufactured with silicone wafer. It also includes a host machine to calculate and analyze the values.

3.Development of actual system: As per the study suggests all above systems have few pros and few cons. To overcome all the cons, we have purposed a highly accurate and precise system that can detect accurate values of nutrients present in the soil.

Figure 1: Block Diagram of Soil Testing System

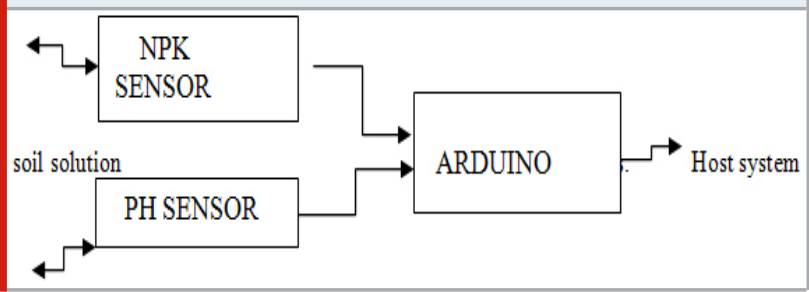

a. Implementation of a ph and npk based sensor system: The system is comprised of a Ph and NPK sensor that are connected to a microcontroller unit that communicates with the sensors and obtains actual value of nutrients present in soil. The values are then used in a neural network-based[3][4] software which analyze them and suggests crops.

\section{b. Block Diagram of the System}

\section{Introduction to sensors used}

Figure 2: $\mathrm{Ph}$ sensor and its interfacing kit

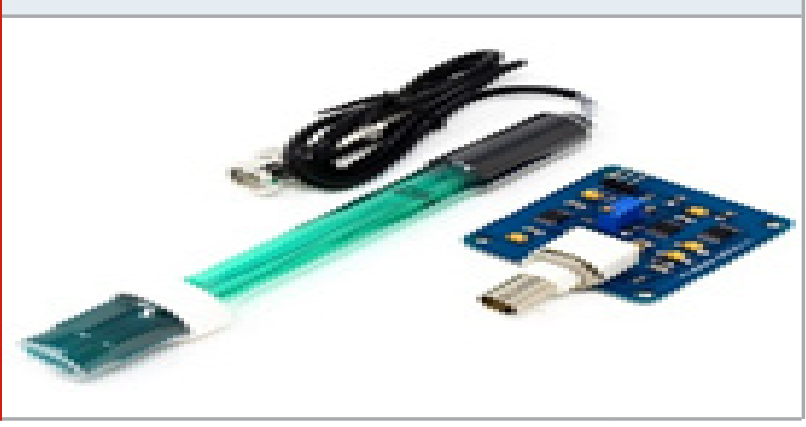

\section{a. PH Sensor}

Figure 3: NPK soil sensor

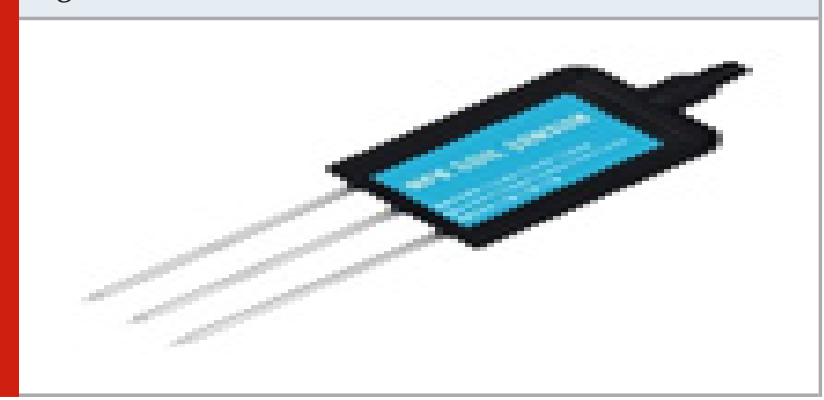

A Ph sensor tell about the acidity and basicity of soil. The presence of $\mathrm{H}+$ ions give information about acidity of the solution and HO- ions give information about basicity of soil. Ph value ranges from 1-14. PH value 1 is highly acidic and $\mathrm{pH}$ value 14 is highly alkaline. $\mathrm{PH}$ value 7 is considered as neutral value.

\section{b. NPK Sensor}

The above NPK sensor is capable of detection of Nitrogen $(\mathrm{N})$, Phosphor (P), and Potassium (K). This sensor is dipped in the soil and electrodes come in contact with soil solution. An electric current of milli-ampere is then passed to the soil solution and it is read by its CPU unit to give actual values of NPK.

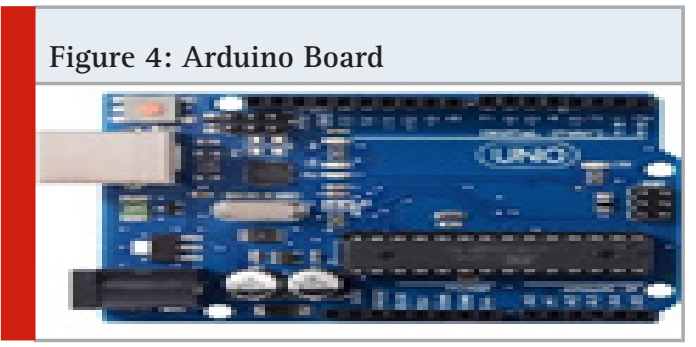




\section{c. Arduino Board}

Arduino board is the main part of the system this actually interfaces $\mathrm{Ph}$ and NPK sensors and reads values from them and passes to the host system terminal. It is a board that has a microcontroller which can process 8bit of data. Fortunately, $\mathrm{Ph}$ and NPK sensor also provide data in digital form of 8 bits.

d. Host Terminal: The host terminal is basically personal computer that runs a software called MATLAB. MATLAB is basically a software program that contents a field called AI and machine learning which is useful in development of required system. The values form $\mathrm{pH}$ sensor and NPK sensor is obtained and provided to this software. This software analyzes the values and suggest crops according to the values entered.

\section{CONCLUSION}

In this review paper, we have studied different soil testing and nutrients acquisition machine. The goal of this paper was to provide an effective as well as efficient solution. For this we have purposed a highly precise and accurate system that not only obtains the nutrients from soil but also provide suggestion for the crop that are suitable for the soil.

\section{ACKNOWLEDGEMENTS}

We are thankful to Govt. of India for launching portal “SOIL HEALTH CARD' from which necessary data have been obtained. The number of sample and values for the training of neural network have been obtained from the above-mentioned website portal.

\section{REFERENCES}

Akhil R, Gokul M S, Sruthi Menon and Lakshmi
S Nair, "Automated Soil Nutrient Monitoring for Improved Agriculture", International Conference on Communication and Signal Processing, April 3-5, 2018, India

Dinesh B. Bhoyar, Shelly R. Wankhede, Swati K. Modod. "Chapter 40 Design and Implementation of AES on FPGA for Security of IOT Data", Springer Science and Business Media LLC, 2020

Dinesh Bhoyar, Barkha Katey, Manish Ingale “ LoRa technology based low cost water meter reading system"Esvier SSRn Information

Dinesh Bhoyar, Barkha Katey, Manish Ingale "LoRa technology based low cost me ter reading system" Esvier SSRn Information Systems and E-business Networks ISSN 1556-5066

Hongyan Chen, Gengxing Zhao, Yinjuan Wang and Long Sui Hu Meng, Discussion on Remote Sensing Estimation of Soil Nutrient Contents Laurent Mazenq, Maurane Marlet, Pierre Temple-Boyer, Céline Durieu , "all-solidstate multimodal probe based on fet electrochemical micro sensors for in-situ soil nutrients monitoring in agriculture"

Mahadeo Mahajan, D. B. Bhoyar "Performance analysis of CDMA under Rayleigh

Nita Kamble, Dinesh Bhoyar," Wireless environment Monitoring System Using Soil Energy" IOSR Journal of Electronics and Communication engineering ISSN 2278-8735, Issue 1 ver iii 2016 PP 40-43

Raden Sumiharto, Reynaldy Hardiyanto, “NPK Soil Nutrient Measurement Prototype Based on Local Binary Pattern and Back-Propagation”, The 2018 IEEE International Conference on Internet of Things and Intelligence System (Iotas) Rician and Nakagami fading channels" Springer Publications Systems and Ebusiness Neyworks ISSN 1556-5066 